Torres Zorrilla, Camilo.

Investigador, Universidad del País Vasco -Euskal Herriko Unibertsitatea. Departamento de Arte y Tecnología.

Universidad Metropolitana de Ciencias de la Educación. Santiago, Chile.

\title{
Imágenes, estrategias y poder; una cuestión más allá del sujeto.
}

TIPO DE TRABAJO

Comunicación.

PALABRAS CLAVE

Sociedad, Imágenes, Sujetos, Control, Dominio.

KEY WORDS

Society, Images, Subjects, Control, Domination.

RESUMEN

Una aproximación crítica al modo de construir imágenes y sus posibles connotaciones sociales, políticas y culturales, nos permite reflexionar en torno a uno de los dilemas de la sociedad contemporánea; el sometimiento al control ideológico a partir del consumo de éstas. La práctica del arte no está alejada de esta problemática y desde ella intentaremos abordar la compleja correspondencia entre la mecánica de producción, el rol del posicionamiento artístico y los efectos que provocan en el cuerpo social.

Una característica de las sociedades "desarrolladas" consiste en favorecer la "libre" circulación y tráfico de imágenes. Este hecho se torna relevante a la hora de entender cómo se viralizan ciertos contenidos a través de los medios de comunicación de masas y redes sociales. Este panorama nos sitúa ante una disyuntiva que nos permite dar cuenta de cómo se establecen ciertos patrones de comportamiento humano, estructurando diferentes maneras de concebir las relaciones entre personas, para finalmente, ahondar en la forma en la qué los sujetos nos veríamos sometidos constantemente a un sistema de dominio voluntario.

Esta comunicación se articula a partir de confrontar dos ejemplos radicalmente distintos de producción audiovisual. El primero, a través del film "Osama", realizado en 2003 por el director afgano Siddiq Barmak, quien aborda la compleja situación de una niña que debe ocultar su verdadera identidad, adoptando patrones masculinos con el fin de sobrevivir a la opresión del régimen talibán. Esta película parte del compromiso por acercarse a temas que establecen distintas posibilidades con aquello que se entiende como "lo real".

Y por otro lado, la performance mega-tecnológica desplegada por la cantante estadounidense Katy Perry en el marco del Super Bowl, 2015. Espectáculo que no escatima recursos para superarse cada año, convirtiéndose en uno de los acontecimientos más vistos y difundidos por millones de personas a través de múltiples dispositivos y "apparatos" digitales.

\section{ABSTRACT}

A critical approach to the manner in which images and their possible social, political and cultural connotations are constructed, enables us to explore one of the dilemmas of contemporary society; subjection to ideological control through consuming them. Art practice is not at a remove from this problematic and will provide us with the point of departure for tackling the complex correspondence between the mechanics of production, the role of artistic positioning and the effects they bring about within the social body. 
It is a characteristic of "developed" societies to encourage the "free" circulation and traffic of images. This circumstance becomes relevant to understanding how some content is viralized through the mass communications media and social networks. This panorama brings us to a juncture that makes it possible to discern how certain patterns of human behaviour are established, structuring different ways of conceiving relations between people, and thereby to uncover the way in which the subject is constantly subordinated to a system of voluntary domination.

This communication is articulated through a comparison between two radically different examples of audio-visual production. The first comes in the shape of the film "Osama" made in 2003 by Afghan director Siddiq Barmak, who approaches the complex situation of a girl who must conceal her true identity, adopting male patterns in order to survive the oppression of the Taliban regime. This film is driven by a commitment to hone in on themes that establish different possibilities via what is understood as "the real".

Then there is the Mega-Techno spectacle unleashed in US singer Katy Perry's performance at the Super Bowl Halftime Show, 2015. A show that spares no expense in order to surpass itself year after year, becoming one of the events to be most seen and disseminated by millions of people through a multiplicity of digital devices and 'app'aratuses.

\section{CONTENIDO}

\section{Maniobras y formas de sometimiento, el dominio voluntario.}

Para situar este apartado abordaremos algunas ideas referidas a la forma contemporánea de dominación social más expandida; el sometimiento al control ideológico través de las imágenes. En un primer acercamiento haremos referencia a la concentración del poder económico a través del monopolio y cómo éste desencadena formas de dominio sobre la comunidad, consecuencia "inmaterial" que se desprende de ese mismo poder ejercido por las grandes corporaciones económicas, -poniendo especial énfasis en el mercado como eje-, y que necesariamente establecen, en nuestro caso, una relación directa entre el desarrollo, la expansión y el negocio de tecnología de última generación.

En una descripción breve, diremos que aquella tecnología no se limita a un reducido grupo de artefactos, nuestro foco de interés estará puesto en lo que denominaremos de aquí en adelante como "apparatos". Éstos poseen ciertas características que los hacen muy apetecibles, de gran atractivo visual, de fácil uso, interactivos y lo más importante para sus creadores, están en constante renovación, actualizando sus servicios y aplicaciones. Sin embargo, también reconoceremos en estas "maravillas" una marca distintiva particular, su obsolescencia programada.

En relación a lo que nos ofrecen, con estos dispositivos podemos generar y visualizar cientos de fotografías, vídeos, películas, cortometrajes, vídeos clips y demás contenido audiovisual. Por otra parte, nos entregan la posibilidad de acceder a una cantidad importante de aplicaciones multimedia, que nos permiten estar en constante comunicación en tiempo real con cientos de personas.

Una última característica que queremos enfatizar es que los usuarios de estos "apparatos" podemos contratar un servicio de conexión y poner a circular en la red aquellos datos que consideramos relevantes, extendiéndolos ilimitadamente.

En nuestro caso específico, nos centraremos en aquella información como imágenes concebidas para retransmitir registros audiovisuales. Este escenario que se ha masificando exponencialmente por el uso de redes infinitas, mediante el supuesto tráfico libre, nos permitirá comprender los procesos de cambio y transformación recientes de nuestra sociedad.

Para ello, el régimen neoliberal se apropia del mercado y controla la venta de productos y servicios para instaurarlo como eje vertebrador de la economía planetaria, a través de sus diversas formas; democracias, tecnocracias, economías de libre mercado y/o mixtas, gobiernos liberales, etc, cada una posee un vínculo característico y que podríamos especificar como aquella relación gestionada por los estados nacionales, mediante alianzas estratégicas con corporaciones privadas en manos de empresarios que poseen la mayor cantidad de riqueza y acumulan las principales fuentes de capital, Terry Eagleton lo menciona y nos entrega alguna cifra.

\section{“(...) la riqueza total de los tres individuos más ricos equivale a la riqueza total de los 600 millones de gente más pobre”. ${ }^{1}$}

Ante este panorama cabe preguntarnos qué rol cumple el sujeto o la ciudadanía frente a los poderosos que traman los destinos del cuerpo social. En este sentido, nos planteamos cómo el dominio ideológico se transforma en la cara visible de esta condición socioeconómica forzada de la población mundial y cómo nos vemos enfrentados al cautiverio por parte de conglomerados multinacionales que se reparten las ganancias de la producción, tal como nos señala Vladimir Lenin.

\footnotetext{
${ }^{1}$ Eagleton, Terry. La idea de cultura. Una mirada política sobre los conflictos culturales. Editorial Paidós. Barcelona, 2010. Pág. 96.

${ }^{2}$ Lenin, Vladímir llich. Imperialismo: la fase superior del capitalismo. Editorial Taurus. Madrid, 2012. Pág. 90.
} 
"Las asociaciones monopolistas de capitalistas (cárteles, consorcios, trust) se reparten entre ellas, en primer lugar, el mercado doméstico, haciéndose de forma más o menos total con la producción del país. Pero, bajo el capitalismo, el mercado interior está ligado inevitablemente al exterior. Ya hace tiempo que el capitalismo creó un mercado mundial" ${ }^{2}$

Ante esta premisa podemos hacer notar que el conflicto por el hegemonía económica no es algo nuevo, muy por el contrario se extiende por casi un siglo, cuando Lenin escribía "Imperialism the Highest Stage of Capitalism" en abril de 1917, ya nos advertía al dilema que nos veríamos envueltos como sociedad, ante las estrategias de sumisión que se desprenden por causa y efecto de aquellas políticas. Ante este escenario, el capitalismo y su expansión, continúa su vertiginoso avance a escala mundial, adaptando definitivamente su técnica global para instalarse como una nueva forma de imperialismo del siglo XXI.

Hoy, las grandes empresas que sustentan este modelo, amplían su alcance a distintas regiones del planeta, diversificando sus negocios y fomentando su competitividad a territorios que explotan con el beneplácito de los gobiernos de turno. En estos países, encuentran las fuentes de suministro y mano de obra, con el objetivo de seguir produciendo sin control alguno. Volviendo a las palabras de Lenin.

"A medida que se acrecentaba la exportación de capitales y que se expandían las "esferas de influencia" y las conexiones con el extranjero y las colonias de las grandes asociaciones monopolistas, el rumbo "natural" de las cosas han conducido al acuerdo internacional entre estas asociaciones y a la formación de cárteles internacionales. Es una nueva fase de la concentración mundial del capital y de la producción". ${ }^{3}$

Una vez realizado este marco contextual, apuntaremos a las repercusiones sociales que podría ocasionar este sistema, ahondando en cómo nos veríamos definitivamente atrapados en mecanismos que actúan como potentes estructuras de inmovilización.

Estaríamos, entonces, frente a una "realidad" re-configurada, desde una perspectiva que surge desde el propio acto voluntario del ser humano. El filósofo coreano Byung-Chul Han traduce lo que nos proponía el estado vigilante descrito por George Orwell en su novela "1984" ${ }^{4}$. Ante la noción del ojo omnipresente que nos vigila, y que se diferencia del naciente panóptico digital, hoy, el real acto de sujeción sería la propia voluntad individual. Esta idea se torna relevante al momento de entenderla como un desplazamiento que transforma el principio orwelliano. Este sujeto no sería consciente de su dominación, sino que de manera inconsciente la aprobaría, dando consentimiento explícito a su forma de opresión, utilizando de manera activa un simulado sentido de libertad y decisión.

Este modelo no contempla desterrar totalmente la idea de control, si no que establece un mecanismo que pone en circulación un nuevo sistema de dominio, adaptado a los tiempos de la sociedad conectada, basado en el estrecho vínculo del poderío de la comunicación digital y la acción cotidiana de hombres y mujeres. Han, lo plantea de esta forma.

"(...) con internet, el Smartphone, las Google Glass, en las que domina la apariencia de la libertad y la comunicación ilimitada. Aquí no se tortura, sino que se tuitea o postea (...). La transparencia y la información sustituyen a la verdad". ${ }^{5}$

De esta forma, estaríamos otorgando a las administraciones políticas, sus gestores y su organización tecnócrata, un medio, una herramienta para mantener eficientes condiciones de vigilancia y control desde y en los sujetos. Mediante técnicas que estarían en directa correspondencia con los adelantos y avances tecnológicos de última generación, que ampliados por los distintos niveles de hiper-comunicación y consumo darán cuenta del mundo simulado que se nos amplía y cautiva, en vez de subyugarnos. Byung-Chul Han lo enfatiza.

"La técnica de poder del régimen neoliberal no es prohibitoria, protectora o represiva, sino, prospectiva, permisiva y proyectiva. El consumo no se reprime, se maximiza. No se genera escasez, sino abundancia, incluso exceso de positividad. Se nos anima a comunicar y consumir (...). No se reprimen las necesidades, se las estimula. En lugar de confesiones extraídas con tortura, tiene lugar un desnudamiento voluntario. El smartphone sustituye a la cámara de tortura". ${ }^{6}$

\section{Esfera pública, espacio y sujetos de acción.}

Para situarnos en este apartado haremos hincapié en el concepto de esfera pública, en breves palabras, lo fijaremos como aquel espacio común que demanda para sí la presencia activa del cuerpo social en la vida pública. Esta aproximación nos plantea una problemática que nos entregará claves para abordar la realidad a partir de aquello que entendemos como lo real o sobre aquello que creemos entender como realidad, lo virtual.

\footnotetext{
${ }^{2}$ Lenin, Vladímir llich. Imperialismo: la fase superior del capitalismo. Editorial Taurus. Madrid, 2012. Pág. 90.

${ }_{3}^{3}$ Lenin, Vladímir Ilich. Imperialismo: la fase superior del capitalismo. Editorial Taurus. Madrid, 2012. Pág. 90

${ }^{4}$ Orwell, George. 1984. Ediciones Destino. Barcelona, 2009.

${ }^{5}$ Han, Byung-Chul. Psicopolítica. Neoliberalismo y nuevas técnicas de poder. Herder Editorial. Barcelona, 2014. Pág. 60

${ }^{6}$ Han, Byung-Chul. Psicopolítica. Neoliberalismo y nuevas técnicas de poder. Herder Editorial. Barcelona, 2014. Pág. 61.
} 
Por un lado, tenemos un espacio en el cual, estamos, vivimos y circulamos cotidianamente, atendiendo a las circunstancias que se generan a partir de acciones creadas por los distintos escenarios de conflicto, la permanente guerra ideológica o la manera de manipular la información a la cual tenemos acceso. Un ejemplo reciente de ello, son la últimas imágenes exhibidas de la catástrofe ocurrida en Nepal, en las que podemos apreciar solamente lo que ha sido filtrado y que "curiosamente" corresponde a una parte del todo, fundamentalmente, a la destrucción de templos y zonas turísticas.

Y por otro, tenemos un espacio virtual ilusorio que nos despega de lo acontecido, ampliándose hasta llegar a un cerco ficticiamente aumentado, obligándonos a dirigir nuestra mirada en busca de la imagen como producto de consumo y satisfacción individual.

Recientemente, mientras los medios mostraban las noticias que hacían eco de la tragedia aérea de la compañía Germanwings, que tuvo lugar en los Pirineos franceses, en Twitter numerosos jóvenes reclamaban contra la suspensión del programa "Mujeres y hombres y viceversa".

Este contexto anteriormente esbozado, se contrapone a uno de los aspectos de la concepción de esfera pública que nos plantea Alexander Kluge, director de cine y escritor alemán,

"La esfera pública entendida como bien común que no tiene precio, era algo que en el siglo XVIII todavía había que ganarle al poder del Estado y a otros poderes". ${ }^{7}$

Lo que propone Kluge, todavía sigue siendo una tarea pendiente. El siglo XXI continúa presentándose como aquel espacio comunitario de la vida social en el que se transa económicamente cada rincón y circunstancia individual. Por lo tanto, sigue manteniéndose como lugar de conflicto entre las fuerzas que dirigen la vida política y social de la comunidad y los agentes que componen esa misma comunidad.

Ante esta premisa, aquella estructura de autoridad dominante la seguimos observando cómo aquello que restringe la autonomía, condicionando nuestra libertad de acción para anular también la posibilidad del pensamiento divergente, debilitando nuestra capacidad de re-pensarnos como sujetos políticos.

La esfera social y los modos de operar en ella, estarían en un estado de relativa neutralización. La dinámica que expande la institucionalidad neoliberal, impone sus políticas sustentadas en una superestructura que capitaliza lo intangible e inmaterial. Rentabiliza, además, el comportamiento y las relaciones entre personas, transformando todo lo que encuentra a su paso, para crear una cultura de mercado que, finalmente, se constituirá como el mayor discurso hegemónico de dominación ideológica de nuestra época.

\section{Imágenes en tensión; industria y espectáculo.}

En las siguientes líneas analizaremos dos producciones audiovisuales y pondremos el acento en la influencia que éstas poseen a la hora de construir ciertos paradigmas o modelos culturales. Para ello, utilizaremos un ejemplo cercano, el conocido portal de internet YouTube, página web que permite a los usuarios, subir, visualizar, descargar y compartir vídeos. Esta idea creada en febrero de 2005 fue adquirida al año siguiente por el gigante cibernético, Google Inc.

Un primer caso, es el vídeo de la actuación de Katy Perry en el Super Bowl $2015^{8}$, que llega a la no despreciable cantidad de 5.468 .438 visualizaciones y en un segundo canal la cifra alcanza las 2.762 .072 reproducciones. En los dos canales consultados, la cifra supera las 8.000 .000 de visitas.

El segundo ejemplo, el film "Osama" ${ }^{9}$ del director afgano Siddiq Barmak, no evidencia de manera explosiva el acceso al link del contenido de dicha película, si no muy por el contrario, al acceder al portal y consultar, podemos dar cuenta que la cantidad de personas que entraron y vieron el vídeo, no supera en un primer canal a los 79.187 visionados, en un segundo a 21.284 y en un tercero, el número se reduce drásticamente a los 817 visitantes, es decir, en tres canales distintos, la cifra supera con dificultad las 100.000 visitas, porcentaje escuálido para los números que se manejan como aceptables y atractivos para dicho sitio.

Dejando atrás las cantidades, diremos que "Osama", nos muestra como a los doce años de edad, una niña afgana que vive con su madre, se debate en la encrucijada de sobrevivir en un medio absolutamente hostil y represivo. Su madre pierde el empleo cuando el régimen talibán asume el poder, cerrando el hospital en el que trabaja y entre las tantas prohibiciones a las que se ven sometidas, ambas no pueden abandonar su casa sin un hombre que actúe de "compañero". Con el marido y el tío fallecido -muertos en combate durante la invasión de la ex U.R.S.S. y la posterior guerra civil- no existen varones que apoyen a la familia. Por lo tanto, éstas no pueden salir y circular por las calles de la ciudad, ante el temor a la detención y la tortura y sin ninguna opción, la niña, se "convierte"

\footnotetext{
${ }^{7}$ Kluge, Alexander. El contexto de un jardín. Discursos sobre las artes, la esfera pública y la tarea de autor. Caja Negra Editora. Buenos Aires, 2014. Pág. 67.

${ }^{8}$ Perry, Katy. Show del descanso del Super Bowl. En YouTube: https://www.youtube.com/watch?v=zy9Wz157wQU [online]. Última consulta abril de 2015.

${ }^{9}$ Barmak, Siddiq. Película: Osama. En YouTube: https://www.youtube.com/watch?v=QYWEuxqntgU [online]. Última consulta abril de 2015.
} 
en un chico llamado Osama, quien logra conseguir un trabajo en una tienda de té y asistir al colegio, pero su "femenina" manera de moverse, hablar y relacionarse con sus pares, despierta las sospechas entre los demás niños de la escuela.

Por otro lado, la cantante estadounidense de nombre artístico Katy Perry, realizaría en el descanso del XLIX Super Bowl, una actuación que deslumbraría a buena parte de las personas que vieron su performance, no necesariamente en vivo y en directo.

Ésta tenía la difícil misión de superar el show que realizara, Beyoncé el año 2014, catalogado por la prensa y los expertos como el mejor show de los últimos años, superando a varios artistas de eventos pasados, algunos de la talla de Michael Jackson, Madonna o Bruno Mars.

La cantante nacida en California prometió mucho color y su intención antes del show, era que la gente hablara de su música. La actuación comenzó con la artista montada sobre un gran león mecánico, cantando su éxito "Roar", continuando con varios cambios de vestuario y apoyada por un cuerpo de baile que incluía, bailarines disfrazados de tiburones, palmeras danzantes, tablas de surf animadas, pelotas de playa con rasgos humanos, mapping, múltiples efectos visuales en tercera dimensión para finalizar "volando".

De esta forma, Perry termina de actuar para sus fans y una audiencia planetaria, que a través de la televisión en directo, cientos de retransmisiones de clips en tiempo real, vía streaming o cuentas en redes sociales, fue estimada en una cifra oficial aproximada de más de 100 millones de personas alrededor de todo el mundo. La cantante cerraría su despliegue escénico con la siguiente frase, Gracias, Dios bendiga a América-, mientras sobrevolaba desde una plataforma con estrellas, el terreno de juego en el que se desplegaba un gran espectáculo de fuegos artificiales, luces, color y brillo.

Para profundizar en esta parte final, podemos plantearnos cómo los sistemas de representación actuales poseen injerencia fundamental en la vida de cada persona, desde una perspectiva crítica entendemos que vivimos en una época en que las diferencias entre realidad y ficción son cada vez más difusas. Éstas se diluyen progresivamente, creando contextos cada vez más imprecisos, y aquello que percibimos se vuelve cada vez más confuso. Es desde este marco que nos cuestionamos el valor -real/virtual- de nuestra dependencia a las imágenes.

Entrando en el análisis de los casos que hemos presentado, vemos que en ambos existe una intención clara de emplear una plataforma de visibilidad y circulación, con el objetivo de llegar a un público específico, esto que pareciese ser algo "normal", se transforma en un mecanismo que permite y asegura una cantidad de receptores que consumen un producto.

Por otra parte, a nivel de tema tratados, destacamos formas opuesta de resolver los guiones de contenido en ambas producciones, existiendo un tipo de montaje diferenciado con intenciones definidas por parte de ambos directores. Uno intentará a través de la espectacularización de un show, lograr altos parámetros de audiencia y éxito, apuntando a la entretención en un momento concreto. $\mathrm{Y}$ el otro, pone de manifiesto el compromiso adquirido, acercándonos a un cierto tipo de problemática social que no es recurrente en los medios masivos.

Ambas creaciones se originan a partir de hechos que marcan una relación estrecha con situaciones cotidianas, una cantante que nos entrega composiciones musicales "irónicas" que nos "hablan" del amor y el desencuentro que éste produce, matizadas con aspectos lúdicos y de entretenimiento. Sin embargo, también recurre a una extraña "infantilización" del espectáculo, a través de una puesta en escena que requiere de la interacción con personajes de marcado carácter infantil e ingenuo, éstos nos remiten a la infancia pasada y animados por una estética de fantasía, pierden toda condición humana.

Y por otro lado, está la recuperación de un caso extraído de la vida real, que pretende entregarnos una mirada acerca de un conflicto que posee características sociales y políticas violentas, para mostrarnos un posicionamiento a través del contenido de la historia rescatada, sin grandes artificios o despliegues escénicos. En este sentido, creemos que el realizador Barmak con su propuesta, modifica e invierte el sentido de lo mostrado por Perry y nos interpela, visibilizando la obligada madurez de una niña que debe asumir sin remedio dicha condición con el propósito de salvar su vida.

Como conclusión, podemos señalar que al haber analizado en profundidad datos, cifras y visionado el contenido de ambos casos, inmediatamente nos han surgido interrogantes acerca de cuál es el interés que suscitan estos disímiles estilos de plantearse el hecho audiovisual.

Estas producciones dan cuenta de cómo existe un conflicto permanente en relación a cómo se vuelven virales y se legitiman diversos registros, mediante estudiadas estrategias de mercado y la "libre" participación ciudadana.

Para cerrar este artículo, hemos considerado importante rescatar algunos de los comentarios publicados por los usuarios.

Usted elige. 
Comentarios sobre el film "Osama". ${ }^{10}$

-La culpa de la deshumanización lo tiene la r..... de EEUU.

-Qué tristeza, que terrible realidad!

-Y yo todo el tiempo hasta el último minuto esperando un final feliz.

-Gracias a Dios, Estados Unidos liberó a esas mujeres de los m... talibanes.

-Si fuera anti-imperialista, diría que esta película es un instrumento de desinformación y adoctrinamiento para validar las atrocidades que realiza Estados Unidos y que no hay nada más alejado de la realidad.

Comentarios sobre la actuación de Katy Perry. ${ }^{11}$

-Volando en un falso fuego artificial cantó, "Fuegos artificiales", montada en un gran león-robot, cantó "Rugido", es como esos vídeos súper literales, interminablemente subidos a YouTube donde las fotos de uso popular, sacadas de un stock, transmiten literalmente cada palabra clave de una canción. Amar a Katy Perry es tan exagerado, que es doloroso.

-¿Era realmente Katy Perry?

-Ella no es la Katy Perry real, ella es la verdadera Katy Perry.

-El que está mal es usted, está ciego!

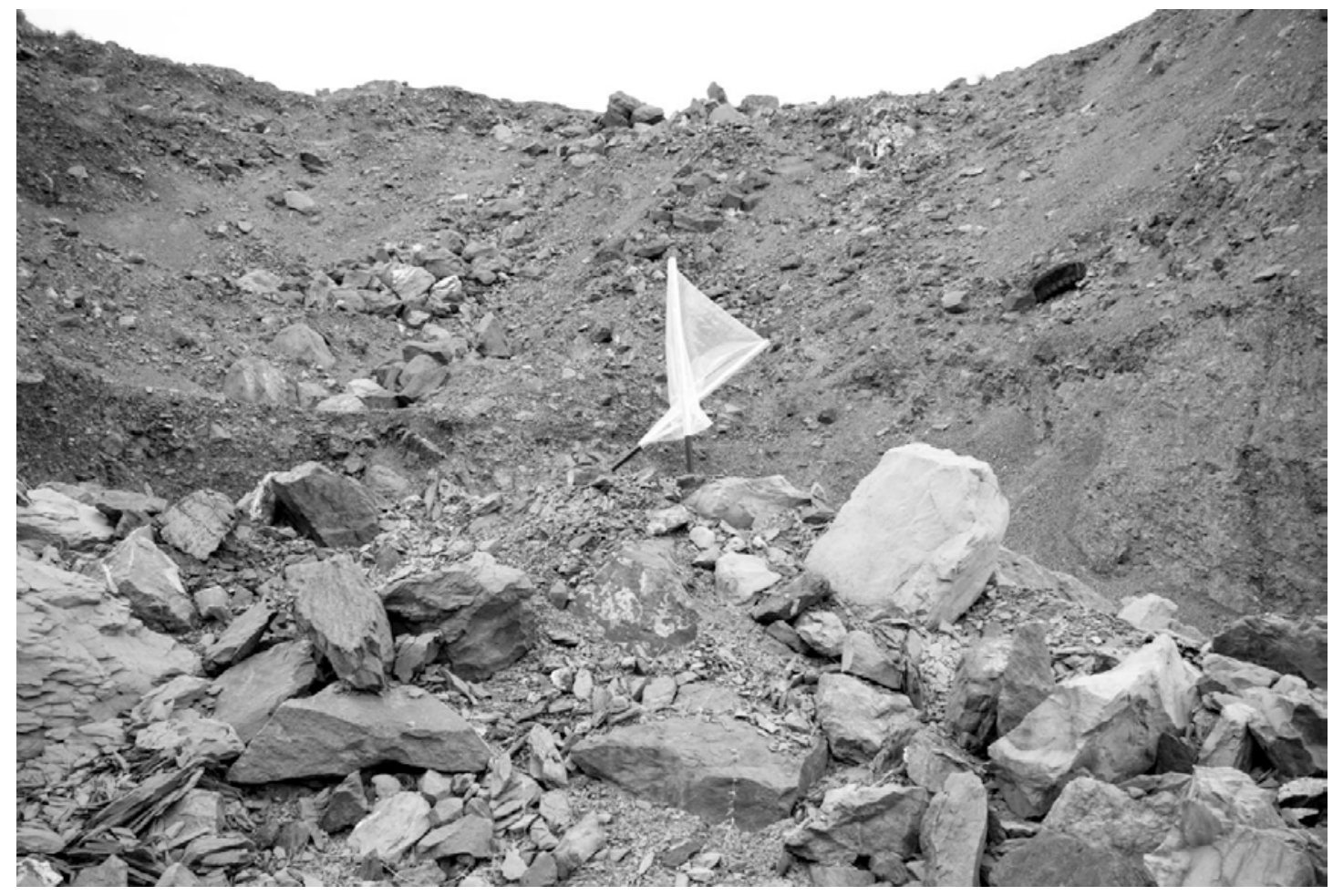

Ilustración 1. Torres Zorrilla, Camilo. Ficciones. (De) una realidad im-probable. Fotografía en blanco y negro sobre caja luz. Parte del proyecto expositivo desarrollado en el Centro Cultural Montehermoso Kulturunea de Vitoria-Gasteiz en 2014.

\footnotetext{
${ }^{10}$ Barmak, Siddiq. Selección de comentarios de la película Osama. En YouTube: https://www.youtube.com/all_comments?v=QYWEuxqntgU [online]. Última consulta abril de 2015. ${ }^{11}$ Perry, Katy. Selección de comentarios del show del descanso del Super Bowl. En YouTube: https://www.youtube.com/all_comments?v=zy9Wz157wQU [online]. Última consulta abril de 2015.
} 


\section{FUENTES REFERENCIALES.}

\section{Bibliografía}

Eagleton, Terry. La idea de cultura. Una mirada política sobre los conflictos culturales. Editorial Paidós. Barcelona, 2010.

Foucault, Michel. Un diálogo sobre el poder y otras conversaciones. Alianza Editorial. Madrid, 2012.

Han, Byung-Chul. Psicopolítica. Neoliberalismo y nuevas técnicas de poder. Herder Editorial. Barcelona, 2014.

Kluge, Alexander. El contexto de un jardín. Discursos sobre las artes, la esfera pública y la tarea de autor. Caja Negra Editora. Buenos Aires, 2014.

Lenin, Vladímir Ilich. Imperialismo: la fase superior del capitalismo. Editorial Taurus. Madrid, 2012.

Orwell, George. 1984. Ediciones Destino. Barcelona, 2009.

Recursos electrónicos.

Barmak, Siddiq. Película: Osama. En YouTube: https://www.youtube.com/watch?v=QYWEuxqntgU [online]. Última consulta abril de 2015.

Noticia en El Correo Digital: http://www.elcorreo.com/bizkaia/culturas/tv/201503/24/fans-mujeres-hombres-viceversa20150324144143.html [online]. Última consulta abril de 2015

Perry, Katy. Show del descanso del Super Bowl. En YouTube: https://www.youtube.com/watch?v=zy9Wz157wQU [online]. Última consulta abril de 2015. 